\title{
El sesgo participativo. Introducción a la teoría empírica de la democracia participativa ${ }^{1}$
}

\author{
Clemente J. N avarro Yáñez \\ Universidad Complutense de $M$ adrid \\ IESA de Andalucía/CSIC \\ Universidad Pablo de O lavide de Sevilla \\ cnavyan@dts.upo.es
}

\section{Resumen}

Este artículo ofrece un marco analítico por el que analizar uno de los model os más relevantes de democracia participativa, la democracia asociativa a nivel local. M ediante la hipótesis del sesgo participativo, el autor muestra los límites de este modelo de democracia: la lógica institucional de la competencia entre partidos imposibilita una distribución igualitaria de oportunidades de participación entre todas las asociaciones locales. D ado que la victoria electoral es el objetivo más importante del gobierno municipal, y que su segundo objetivo, la oferta de participación, significa distribuir el poder municipal, al hacer lo segundo, debe seleccionar aquellas asociaciones que no limiten el primer objetivo. Para contrastar la hipótesis, el autor analiza experiencias de democracia asociativa en municipios españoles.

Palabras clave: democracia participativa, democracia asociativa, participación ciudadana, municipios.

Abstract. The participatory bias. An introduction to the positive theory of participatory denocracy

This article offer an analytical framework to analyse one of the most relevant models of participatory democracay, the associative democracy in the local level of government. By the participatory bias hypothesis, the author show the structural limits of this model

1. Este artículo se basa en la tesis doctoral del autor, Innovación democrática en el sur de Europa. La experiencia municipal en Italia y España (1960-1995), que ha recibido el Premio Extraordinario de Tesis D octoral de la U niversidad Complutense de M adrid (curso 19961997. El autor quisiera agradecer al Ayuntamiento de Córdoba (Corporación municipal 1991-1995) y al CSIC la financiación recibida para realizar la investigación en que se basa la tesis y el texto. Éste fue presentado con anterioridad en el Seminario sobre la D emocracia del IESA de Andalucía (junio de 1998), en conferencias en la Universidad Federal Rural de Rio de Janeiro y la U niversidad Federal de U berlandia en Brasil (agosto de 1998) y en el VI Congreso Español de Sociología (septiembre de 1998). H e de agradecer también los comentarios y sugerencias de los alumnos del programa de doctorado «D erechos $\mathrm{H}$ umanos y D esarrollo (1999-2000)» de la Universidad Pablo de O lavide, así como las aportaciones de M anuel Pérez Yrueta y Fernando Aguial (IESA de Andalucía/C SIC). 
of democracy: the institutional logic of party competence make imposible an igualitarian distribution of participation opportunities among local associations. While the main goal for local government is the electoral victory, and its second goal, the participation opportunities supply, means redistribution of local power, to implement the second one has to select those associations that does not limit the firts one. To contrast the hypotesis, the author analyse the development of some associative democracy experiences in spanish municipalities.

Key words: participatory democracy, associative democracy, citizen participation, municipalities.

\section{Sumario}

1. La democracia participativa como «democracia asociativa» a nivel municipal 2. Introducción a la teoría empírica de la democracia participativa
3. Análisis empírico de experiencias de democracia participativa en municipios españoles

4. El sesgo participativo: límites estructurales a la democracia participativa

Bibliografía

Como es bien conocido, la reflexión sobre la democracia ha ido adoptando desde finales del siglo pasado dos vertientes, una normativa y otra empírica o positiva. La primera, centrada en la proposición de modelos acerca de la mejor forma en que puede adecuarse el funcionamiento de este sistema de gobierno a sus postulados normativos, se ha desarrollado tanto para la democracia representativa de competencia entre partidos - 0 poliarquía electoral (Sartori, 1988) - como para la democracia participativa. En cambio, la teoría empírica, que ha hecho del funcionamiento real de la democracia su objeto de análisis, se ha centrado casi exclusivamente en la primera, siendo las aportaciones empíricas sobre la democracia participativa casi inexistentes.

En todo caso, y a partir de mitad de los ochenta, han ido apareciendo propuestas de reforma institucional por las que adecuar la dinámica de la democracia participativa a sus postulados normativos. Si bien, no se han desarrollado modelos que permitan evaluar el funcionamiento real de tales propuestas. Q uedando, por tanto, la reflexión en el campo de la teoría normativa, esto es, como teoría normativa de la democracia participativa.

Este texto pretende avanzar en el análisis empírico de este modelo de democracia, realizando un acercamiento a lo que podría denominarse teoría empírica - o positiva - dela democracia participativa. M ás concretamente, se tratará de formular un modelo que, atendiendo a las propuestas normativas y a los rasgos básicos de las poliarquías el ectorales, dé cuenta de la dinámica que previsiblemente seguirá la democracia participativa.

Para ello, el primer apartado pone de manifiesto cuáles son los rasgos concretos de las propuestas normativas. El segundo, tomando las aportaciones de 
la teoría empírica downsoniana (D owns, 1973, 1991), da cuenta de un conjunto de hipótesis por el que estudiar empíricamente la democracia participativa. Estas hipótesis se tratan de contrastar empíricamente en el tercer apartado a través de experiencias concretas en las que se han puesto en marcha algunas de las iniciativas normativas comentadas en el segundo apartado. El texto se cierra con unas breves conclusiones acerca de las implicaciones teóricas y prácticas de lo expuesto con anterioridad.

\section{La democracia participativa como «democracia asociativa» en el ámbito municipal}

Las aportaciones más sobresalientes sobre la democracia participativa, a las que suele denominarse democracia asociativa o democracia corporativa, señalan que ésta debe consistir en la complementación de los mecanismos de participación electoral, articulados a través de la competencia de partidos, mediante cierta oferta de oportunidades de participación que permita la inclusión de los grupos y asociaciones civiles en los procesos de toma de decisiones ${ }^{2}$. Se trataría, pues, de complementar, articular y regular de forma estable, mediante mecanismos institucionales, las dos esferas por las que tiene lugar la participación de los ciudadanos en las democracias contemporáneas: la electoral y la corporativa - 0 de presión (Schmitter, 1992). La primera debería subsistir como mecanismo legítimo de acceso al poder político, la segunda debería constituirse como vía por la que solventar los problemas de gobernabilidad que enfrentan los sistemas democráticos. Para ello, los grupos de representación de intereses deben canalizar la demanda política y además hacerse cargo de la gestión de al gunas políticas públicas y la provisión de ciertos servicios. Por su parte, el gobierno debe propiciar oportunidades de participación, facilitando tanto la formación y actuación de los grupos, como su inclusión en los procesos de toma de decisiones.

Algunas de estas reflexiones aportan, además, propuestas concretas de reforma institucional, tal y como la Associative D emocracy de H irst (1994), la Corporative D emocracy de Schmitter (1988) o M ansbridge (1995), las reflexiones sobre Associations and Democratic Governance de Cohen y Rogers (1995), así como las aportaciones que aparecen en este mismo volumen. Para estos autores, se trata de recuperar el carácter deliberativo de la democracia mediante la inclusión de grupos de representación de intereses en los procesos de toma de decisiones, de forma directa y adoptando un papel formal en las labores de gobierno.

Estas propuestas se basan en la hipótesis de que los grupos de representación de intereses son construcciones políticas, órganos artificiales sobre los que, por tanto, pueden actuar las agencias gubernamentales para que contribuyan a aumentar la calidad de las democracias. En este sentido, el

2. Entre otras pueden consultarse las aportaciones de K elso (1978), D ahl (1982: cap. 8; 1992: cap. 23); Barber (1986), H eld (1986), H irts (1994) o C ohen y Rogers (1995). 
gobierno no debe limitarse a crear procesos de inclusión de carácter corporativo, sino que debe asegurar que todos los intereses estén presentes, incluso fomentando la creación de asociaciones y grupos, así como actuando sobre el ambiente de éstos para que se orienten democráticamente hacia los procesos de toma de decisiones (C ohen y Rogers, 1995: 46-48; H irst, 1995: 102-107).

Se trata, pues, de desarrollar un amplio e intenso proceso de facilitación con respecto a la trama corporativa a través de la aplicación de incentivos de

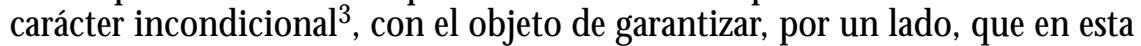
trama estén presentes todos los intereses y, por otro, que los grupos se orienten en su acción bajo los principios de una cultura política democrática - bien público, prudencia, tolerancia, solidaridad... (D iamond, 1994).

$M$ ás concretamente, los instrumentos que se proponen para llevar a cabo este tipo de reformas institucionales son fundamentalmente de dos tipos, los cuales deben darse de forma complementaria. Por un lado, los instrumentos convencionales de las políticas públicas (tasas, subsidios, subvenciones, sanciones legales... ), que deben actuar como incentivos sobre las asociaciones. Por otro lado, la aplicación y desarrollo de esos instrumentos mediante los procedimientos formales de toma de decisiones característicos del gobierno democrático (cuerpos legislativos y administrativos, así como tribunales de justicia) (C ohen y Rogers, 1995: 44; Schmitter, 1995: 172-173). En este sentido, las oportunidades de participación pueden sintetizarse en, por un lado, el acceso a bienes y servicios públicos y, por otro, el acceso a órganos de toma de decisiones.

0 tro de los puntos comunes a estas propuestas de «democratización de la democracia» hace hincapié en la escala local como locus apropiado de las reformas. La existencia de cierta relación de adecuación entre democracia participativa y nivel de gobierno local es un elemento indiscutible de la teoría democrática, pues la participación activa de los ciudadanos, directamente 0 a través de asociaciones, aumenta en la misma medida en que disminuye el tamaño de la comunidad política (D ahl y Tufte, 1973; D ahl, 1982: 13; Sartori, 1988: 92). Pero, además, los ciudadanos se identifican y se orientan políticamente hacia el gobierno municipal en mayor medida que hacia cualquier otro 4 .

En suma, la democracia participativa consistiría en la provisión u oferta de oportunidades de participación a grupos de representación de intere-

3. Sobre el concepto de facilitación, antónimo de represión, se remite a Tilly (1978). Sobre las diferencias entre incentivos condicionales (que actúan directamente sobre el orden de preferencias de los actores) y los incondicionales (que actúan sobre el marco o ambiente de actuación de los actores) se remite a D owding (1991).

4. Para una discusión más amplia de la relación de adecuación entre escala y forma de gobierno democrática, la relevancia política de los municipios en las democracias de los países desarrollados, así como el análisis de experiencias y modelos de democratización a nivel municipal, se remite a N avarro (1998). 
ses por parte de unidades de gobierno de tamaño reducido, como por ejemplo los municipios. De hecho, este tipo de iniciativas vienen siendo comunes en municipios de los países desarrollados (N avarro, 1988: cap. 3). Entre éstas, destaca el caso español, ya que al rededor de tres cuartas partes de sus municipios han puesto en marcha reformas institucionales para propiciar la participación de los ciudadanos, cuyos ejes orientadores básicos coinciden con las propuestas que vienen produciéndose desde la teoría democrática. Esto permite analizar empíricamente las propuestas normativas que al respecto vienen realizándose.

\section{Introducción a la teoría empírica de la democracia participativa}

Ahora bien, ¿cómo cabe esperar que funcione de hecho el modelo de «democracia asociativa» descrito más arriba?, ¿en qué forma interactuarán gobiernos municipales y grupos de representación de intereses? Para conocerlo se describirá el sistema de acción objeto de análisis (actores intervinentes, recursos, intereses y marco institucional), para posteriormente determinar sus posibles pautas de interacción. En este sentido, debe señalarse previamente que los sistemas de gobierno municipal de las democracias occidentales pueden clasificarse en dos grandes tipologías o modelos: descentralizado y desconcentrado. En el primero, común a toda la Europa continental y América Latina, los municipios poseen «competencia general» sobre los asuntos locales, esto es, pueden actuar de forma autónoma con respecto a niveles de gobiernos superiores. En cambio, en el modelo desconcentrado o «anglosajón», la acción municipal es delimitada por el gobierno central o los gobiernos federales (N avarro, 1998a). N uestro análisis, y por tanto su validez, se centrarán en el primer modelo, pues es en éste en el que los gobiernos municipales poseen el monopolio de la oferta de oportunidades de participación política a nivel municipal.

\subsection{El sistema político local: actores, recursos e intereses}

Al igual que en otros niveles de gobierno, la participación política en los municipios se articula a través de las esferas electoral y corporativa, en donde clase política - integrantes del gobierno municipal o la oposicióny élites cívicas - miembros activos de los grupos de representación de intereses- son sus actores principales. Ahora bien, estos actores poseen características peculiares derivadas de su localismo que inciden de una forma determinante en el desarrollo de las iniciativas de democratización a nivel municipal.

Los gobiernos municipales poseen un diseño institucional que se corresponde con el modelo de democracia de competencia entre partidos. Este proceso es el que legitima el acceso al poder político y el que concede al partido o coalición victoriosa el monopolio del aparato gubernamental y de los recursos y bienes municipales. D e esto se desprende lo siguiente. Primero, que 
el objetivo principal de los partidos reside en la maximización de los votos para obtener el poder. Por tanto, y en segundo lugar, que el interés principal del partido que controla el gobierno local consiste en ser reelegido. Por último, que el partido gobernante puede hacer uso del aparato gubernamental y los bienes municipales de la forma que le parezca para favorecer su reelección (D owns, 1973, 1991).

Ahora bien, en el caso del gobierno municipal, la interacción entre clase política y ciudadanía es más intensa y constante que en otros niveles de gobierno. Por tanto, para desarrollar su labor estos actores necesitan anclajes directos con la comunidad local (Rao, 1998; O wens, 1998), entre los que destaca la pertenencia a grupos de representación de intereses. D e hecho, datos al respecto muestran que por lo común los miembros de la clase política local pertenecen simultáneamente a uno o más grupos 0 asociaciones locales (Parry y otros, 1992: 352; Balme, 1989: 140; M oyser y Parry, 1989: 160-162; Bettin, 1993). Lo que muestra la existencia de una intrincada red de interacciones entre partidos y asociaciones locales, y por tanto, un nivel de interdependencia más alto y extendido que en otros niveles de gobierno.

Por su parte, las asociaciones locales, dado su carácter de grupos de interés con la finalidad de obtención de bienes públicos y, entre éstos, oportunidades de participación en la política municipal, presentan constricciones estructurales relevantes en relación con el fenómeno que aquí se analiza ${ }^{5}$. Se trata de acciones colectivas sometidas a rendimientos marginales decrecientes, pues a medida que aumenta la cooperación disminuye el valor de nuevos apoyos individuales, incluso llegando éstos a carecer de efecto o ser negativos (H ardin, 1982: 17-20; Elster, 1989: 128-132; M arwell y O liver, 1993: 40). Ello hace que se trate de grupos pequeños e inestables constituidos por una pequeña élite cívica o masa crítica que, contando con un al to interés en la consecución de ciertos bienes públicos y numerosos recursos, corren con los costes de movilización y organización que conlleva la acción colectiva (O liver, 1984; Bolduc, 1980).

D e lo anterior se deriva que se trata de grupos estructuralmente dependientes. La influencia que puedan ejercer depende más de la consecución de recursos externos que de los que provienen de sus miembros. En concreto, de la posición que ocupen en la trama asociativa local y de la superposición que mantengan con otros actores políticos (grupos, partidos o gobierno municipal). Cuanto más central sea la primera y más alta la segunda, mayor será el acceso a información y recursos, y, por tanto, su capacidad de influencia (Knoke, 1990: 69-74; M arwell y O liver, 1993: cap. 5; Knoke y Kuklinski, 1982: 52; Klandermans y O neaga, 1987).

En suma, los rasgos básicos del sistema político local serían los siguientes:

5. En adelante se tratarán como sinónimos los términos grupos de representación de intereses, grupos o asociaciones locales. 
1. La competencia electoral entre partidos constituye la lógica institucional que configura, organiza y delimita los procesos que tienen lugar en la esfera electoral, pues legitima el acceso al ejercicio del poder político en la comunidad local.

2. Como derivación de lo anterior, el partido o coalición que controla el gobierno municipal posee el monopolio de la oferta de oportunidades de participación.

3. Los grupos y asociaciones locales se caracterizan por ser estructuralmente dependientes. $D$ ependen de fuentes externas de recursos para hacer frente a los costes derivados de la producción de acción colectiva.

4. De lo anterior se deriva que su capacidad de influencia depende de la centralidad y la superposición que mantengan en la trama corporativa local. Cuanto más altas estas últimas, mayor será la primera.

\subsection{Pautas de interacción: el sesgo participativo}

En términos generales, las reformas institucionales y, en concreto, la institucionalización de cierta oferta municipal, las oportunidades de participación, suponen procesos de movilización de recursos políticos. Por esta razón, su origen y desarrollo dependen de la existencia de una coalición de actores, tanto el ectorales - partidos - como corporativos - grupos- que tengan recursos suficientes como para poner en marcha, o incluso imponer, el proceso (Lanzalaco, 1995). Si por coalición entendemos un acuerdo de carácter contingente entre diversos actores sobre las reglas de comportamiento que harán posible que cada uno de ellos alcance sus intereses y de una forma más bene ficiosa que individualmente o mediante otros acuerdos o alianzas (O rdeshook, 1992: 258), resulta evidente que el gobierno municipal debe tener en cuenta los recursos e intereses de los actores políticos locales.

M ás aún, la oferta de oportunidades de participación supone un proceso de redistribución del poder 0 , cuando menos, de creación de canales por los que influir sobre el gobierno municipal. El hecho de que éste pretenda hacerlo al mismo tiempo que pretende ganar las elecciones crea un dilema acerca de qué actores de todos a los que puede ofrecer oportunidades de participación harán posible la consecución de ambos objetivos. Además, los partidos de la oposición también tratarán de canalizar la demanda para formar coaliciones político-cívicas, aprovechando el proceso de redistribución del poder que supone la oferta de oportunidades de participación para erosionar 0 arrebatar la posición de gobierno a otros actores de la esfera electoral.

D ado este dilema, podría postularse que para generar una coalición favorable y poderosa, el gobierno municipal tendrá en cuenta información relevante sobre los recursos y los intereses de las asociaciones locales. En concreto, sus coeficientes de influencia y de confianza. El primero se refiere de la centralidad de los grupos en la trama corporativa y, por tanto, a su capacidad de influencia. El segundo da cuenta de la superposición que mantiene con el 
gobierno municipal, los rasgos comunes de sus respectivos sistemas de creencias, de los que se derivan expectativas de apoyo mutuo ${ }^{6}$.

Es previsible que aquellas asociaciones que por su centralidad - coeficiente de influencia - garanticen la disponibilidad de recursos suficientes para colaborar con el gobierno municipal, como por ejemplo, mediante la transmisión de información acerca de las preferencias u opiniones de los ciudadanos, mediante la colaboración en el desarrollo de una actividad o proyecto municipal, o incluso en la movilización o campaña electoral, accedan en mayor medida a las oportunidades de participación que otras que no lo garanticen. Pero, al mismo tiempo, deben garantizar cierta predisposición a hacerlo - coeficiente de confianza.

D e lo anterior se deriva que, en cuanto a su forma, la oferta municipal de oportunidades de participación tenderá a presentar cierto sesgo participativo, por el que se ben eficiará a determinados grupos en particular frente a otros. Así pues, nuestra hipótesis acerca de la distribución municipal de oportunidades de participación podría formalizarse como sigue:

$$
O P_{g i}=f\left(\mathrm{Cl}_{g i}, C C_{g i}\right) \text {; }
$$

donde:

$O P_{\text {gi }}$ : oportunidades de participación del grupo i,

$\mathrm{Cl}_{\mathrm{gi}}$ : coeficiente de influencia del grupo i,

$\mathrm{CC}_{\mathrm{gi}}$ : coeficiente de confianza del grupo i.

Además, esta hipótesis implica que el gobierno municipal procederá a institucionalizar la oferta, a incorporarla como una política pública en su proyecto de gobierno, siempre y cuando existan actores corporativos que cumpliendo tales condiciones garanticen la consecución simultánea de democratización y victoria electoral. Pues, en cualquier caso, es previsible que en la ordenación de preferencias del partido o partidos que controlen el gobierno municipal la victoria electoral se sitúe siempre en una posición jerárquicamente superior a la iniciativa de democratización. En términos más sencillos, la segunda estará condicionada por la primera, aunque sólo sea porque para proveer el bien público «oportunidades de participación» es necesario estar en situación de gobierno.

En suma, la hipótesis del sesgo participativo supone que éste es un efecto institucionalmente inducido por el marco o estructura de oportunidades donde tiene lugar. La lógica institucional que regula el acceso al poder municipal, la victoria electoral - la maximización de votos- condiciona el resul-

6. Por sistema de creencias se entiende la forma e intensidad con la que las cuestiones políticas son conceptualizadas y entendidas por diversos actores (Sartori, 1987: 83-103). En nuestro caso se trataría de las creencias acerca de los problemas o cuestiones que debe abordar la política municipal y la forma en que debe hacerlo. 
tado del proceso democratizador, pues fuerza cierto sesgo en la distribución de oportunidades de participación.

\section{Análisis empírico de experiencias de democracia participativa en municipios españoles}

Tal y como se ha indicado más arriba, alrededor de tres cuartas partes de los municipios españoles han puesto en marcha procesos de institucionalización de oportunidades de participación siguiendo las orientaciones básicas que delimitan las propuestas normativas expuestas anteriormente. Esto permite contrastar empíricamente nuestras hipótesis acerca del funcionamiento de tales modelos de democracia participativa. Fundamentalmente, estas iniciativas han consistido en la elaboración y aprobación de un reglamento o norma de participación ciudadana (RPC, en adelante). Se trata de un documento normativo por el que se crea una institución política que tiene por objetivo regular de forma estable la relación entre gobierno y comunidad local, garantizando así cierta oferta pública de oportunidades de participación?.

Para contrastar lo apuntado en nuestro modelo se tomarán estas experiencias como corpus empírico, realizando en primer lugar un breve análisis de estas iniciativas para el conjunto de los municipios españoles de 20.000 0 más habitantes a través de una encuesta postal ${ }^{8}$. Posteriormente, se analizan dos estudios de casos, que se corresponden con dos de los municipios que fueron pioneros en la puesta en marcha de tales procesos.

\subsection{La democratización municipal: la coalición democratizadora «partidos de izquierda-asociaciones vecinales»}

En 1993 alrededor del 63\% de los municipios españoles de 20.000 o más habitantes habían puesto en marcha el proceso de democratización municipal mediante la aprobación de un RPC. EI 26,7\% de éstos se aprobaron con anterioridad a la aparición de la Ley Reguladora de Bases de Régimen Local

7. Sobre la importancia relativa de las experiencias de aprobación de RPC en España frente a otros tipos de iniciativas de carácter específico (colaboración en programas o proyectos municipales, preparación de fiestas populares, etc.), se remite a N avarro (1997a), en donde se definen diversos modelos de democratización a través del análisis estadístico multivariable de 27 estudios de caso de experiencias de participación ciudadana en municipios españoles.

8. Los datos se han tomado de la encuesta postal «Participación Ciudadana en los M unicipios» que realizó la FEM P en 1993. Q uisiera agradecer a esta institución (a la Comisión Permanente de Participación Ciudadana) su confianza al encargarme la organización, explotación y análisis de los datos. Los resultados fueron presentados en un informe a la Comisión Permanente en junio de 1994. Cf. N avarro (1994). Los datos deben tomarse con precaución debido a la baja tasa de respuesta, que puede elevar el error muestral hasta el $5 \%$, que se incrementa al hacer cruces, ya que las submuestras son muy reducidas. 
(LRBRL) en 1985, por la que se regula el desarrollo de este tipo de procesos para todos los municipios.

Tomando como criterio esta fecha y al gunos resultados del análisis, pueden diferenciarse dos tipos de municipios. Por una parte, municipios innovadores, pues pusieron en marcha los procesos con anterioridad a la aprobación de la LRBRL; por otra parte, municipios imitadores, lo hicieron con posterioridad y, además, la morfología de sus RPC se ajusta a lo recogido en la legislación, que, fundamentalmente, se basa en las experiencias desarrolladas en los municipios innovadores (N avarro, 1999: 154-158).

En su conjunto, los datos de la encuesta muestran que el fenómeno aumenta en la misma medida que lo hace el tamaño del municipio, y que se da en mayor medida entre los municipios que cuentan con un gobierno encabezado por partidos de izquierda (PSO E e IU ) que cuando se trata del PP o partidos nacionalistas. Rasgos que se acentúan cuando se trata de los municipios innovadores (figuras 1 y 2 ) $^{9}$. Si se atiende a ciertos rasgos del proceso de elaboración de los RPC - actores promotores y aportación de sugerencias por parte de las asociaciones- , se puede comprobar que la colaboración entre gobierno municipal y asociaciones locales es menor entre los municipios imitadores, y sobre todo cuando se trata de municipios de menor tamaño o gobernados por el PP o partidos nacionalistas (figura 3).

En el marco de nuestras hipótesis, estas diferencias pueden explicarse en función de la morfología de las tramas corporativas locales en los municipios españoles y la superposición existente entre asociaciones y partidos. Por una parte, la trama corporativa municipal en España se ha caracterizado hasta finales de los ochenta por la presencia activa y casi exclusiva de asociaciones de vecinos (AA.VV., en adelante) (Sastre, 1997). Éstas han seguido conservando cierta centralidad con posterioridad, cuando la trama ha aumentado en volumen, pero, sobre todo, se ha diversificado, en atención a nuevos intereses o preocupaciones (asociaciones de jóvenes, deportivas, ecologistas, de mujeres, de ancianos, culturales, etc.) (Fundación Encuentro, 1994, 1995; Pietro-Lacaci, 1994; M artín y Francescuti, 1993).

Por otra parte, es conocido el al to grado de superposición existente entre asociaciones vecinales y los partidos de izquierda, sobre todo durante los primeros años de la transición y consolidación democráticas en España, y en especial con el PCE, posteriormente partido mayoritario de la coalición IU (Castell, 1986: 314-316; Capó y otros, 1988: 204; Villasante, 1984; Gun-

9. En las figuras 1, 2 y 3 se refleja el indicador diferencia de proporciones. Para determinar la intensidad del fenómeno se resta el porcentaje de municipios que no han aprobado RPC para cada categoría de las variables independientes del porcentaje de municipios que sí lo han hecho en esa misma categoría. El mismo procedimiento se aplica al restar el porcentaje de los que aprobaron el RPC antes de 1984 menos los que lo hicieron con posterioridad. En la ilustración 2 los cálculos serían los siguientes. Para la iniciativa, que en la ilustración 3 aparece como IER (iniciativa elaboración reglamento) sería: (clase política +élite cívica) - (clase política en exclusiva). Para las aportaciones: Sí-N o. 


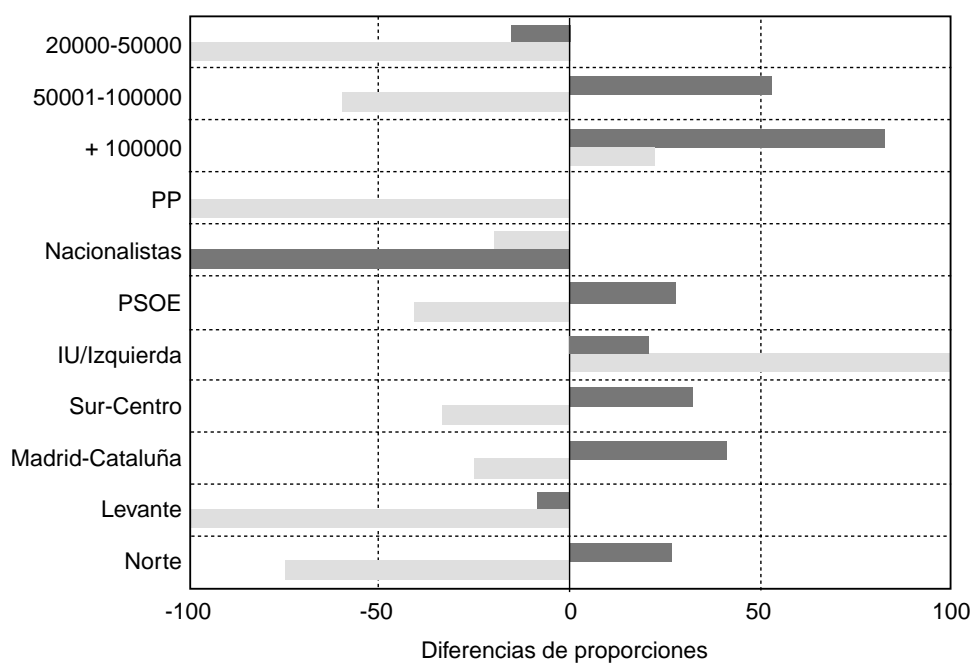

\begin{tabular}{|ll|l|l|l|c|c|c|c|c|c|c|c|}
\hline Intensidad & $-15,2$ & 52,8 & 82,6 & 0 & -20 & 27,6 & 20 & 32 & 40,8 & $-8,4$ & 26,4 \\
\hline Antes-después 1984 \\
$\square$ & -100 & -60 & 22,2 & -100 & -100 & $-40,8$ & 100 & $-33,4$ & -25 & -100 & -75 \\
\hline
\end{tabular}

Figura 1. Intensidad y período de aprobación de RPC en municipios españoles según tamaño del municipio, partido y zona geográfica (1979-1993).

Fuente: N avarro (1999: 152).

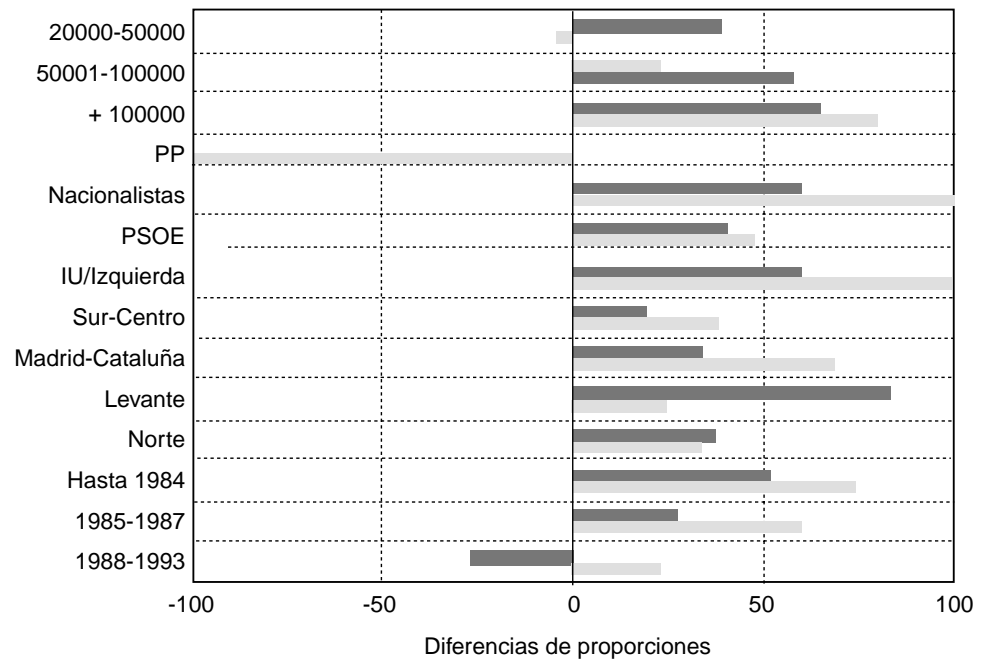

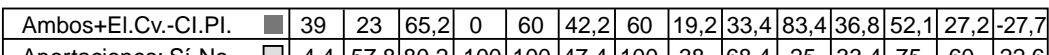

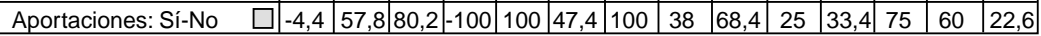

Figura 2. Colaboración entre gobierno municipal y asociaciones en la elaboración del RPC según tamaño del municipio, partido y zona geográfica (1979-1993).

Fuente: $\mathrm{N}$ avarro (1999: 153). 


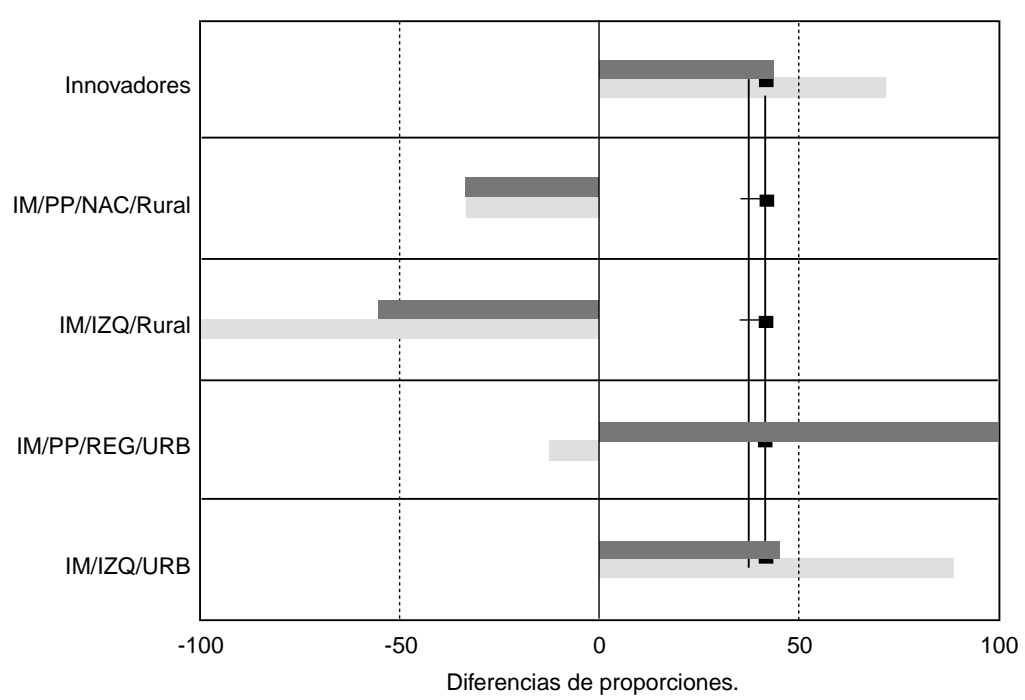

IER (Ambos-Cl. pol.) + IER: Media total $\square$ Aportaciones (Sí-No)

Aportaciones: Media ti

Figura 3. C olaboración entre gobierno municipal y asociaciones en la elaboración del RPC según tipos de municipios (1979-1993).

Fuente: N avarro (1999: 158).

ter y otros, 1986). Ambos actores compartían como objetivos prioritarios de la política municipal establecer mecanismos y canales de participación, así como reorientar las políticas de ordenación urbana. En cambio, la superposición entre partidos y nuevas asociaciones es menor, más dispersa, o al menos, menos selectiva que en el caso de las vecinales (U rrutia, 1992). En un momento en que, además, la agenda de actuación municipal tiende a centrarse en la provisión de servicios sociales, como corolario del proceso de conformación y posterior descentralización del Estado de bienestar en España, y menos en el urbanismo, problema central de la agenda de actuación de las asociaciones de vecinos ( $\mathrm{N}$ avarro, 1997a).

En el caso de los municipios innovadores, parece evidente que la conjunción de la centralidad de las asociaciones de vecinos y su superposición con los partidos de izquierda propiciaron la creación de una coalición poderosa que impulsó el proceso democratizador a través de RPC allí donde los segundos gobernaban. Por contra, los cambios en las tramas corporativas han supuesto la debilitación de las coaliciones que desarrollan el proceso en los municipios imitadores, sobre todo cuando la colaboración - confianzaentre partidos y asociaciones disminuye. En este caso, cuando se trata de municipios menores o gobernados por otros partidos, la iniciativa parte en mayor medida del propio gobierno municipal, en lo que también se debe 
tener en cuenta el refuerzo legitimador que supone la aprobación de la LRBRL.

Ahora bien, estos resultados informan de la coalición que da origen al proceso, pero no permiten confirmar que exista sesgo participativo en su desarrollo. Para contrastar este fenómeno se exponen a continuación los resultados de dos estudios de caso de municipios innovadores, en concreto, Córdoba y M álaga, que cuentan con aproximadamente 300.000 y 500.000 habitantes respectivamente.

\subsection{D os estudios de caso: la oferta de oportunidades de participación en Córdoba y M álaga (1979-1995)}

Tanto en Córdoba como en M álaga se ha producido una intensa relación entre asociaciones locales y gobierno municipal desde las primeras elecciones democráticas en 1979. En ambas ciudades han gobernado ininterrumpidamente hasta 1995 partidos políticos programáticamente interesados en promover y ofrecer oportunidades de participación (PCE/IU en Córdoba y PSO E en M álaga). D e hecho, aprueban sus primeros RPC en 1979 y 1981 respectivamente. Estos y sus sucesivas modificaciones reflejan un model o de democracia asociativa similar a las propuestas normativas expuestas más arriba. Se crean órganos de participación, en los que las asociaciones pueden influir sobre los procesos políticos municipales, y se conceden, al menos anualmente, subvenciones y ayudas económicas a las asociaciones locales, como concreción del ejercicio de facilitación del gobierno municipal con respecto a ellas.

El análisis de la composición de los miembros de los órganos de participación, Consejos de D istrito y Consejos de C entro Cívico en el caso de Córdoba, y Plenos de Distrito en M álaga, así como la distribución de las subvenciones concedidas por estos gobiernos municipales con el fin de fomentar el asociacionismo y la participación ciudadana, muestran la existencia de cierto sesgo participativo, y aún más, la conformación de ciertas comunidades políticas diferenciadas según el grado de acceso a oportunidades de participación, y más en general, según las pautas de interacción establecidas entre asociaciones y gobierno municipal.

D e forma sintética los resultados del análisis se muestran en las tablas 1 y 2 . En ellas se pone de manifiesto el coeficiente de confianza e influencia de las asociaciones, como variables independientes de nuestro modelo, y las pautas de interacción, acceso a los órganos de participación y a las subvenciones, como variables dependientes (también reflejadas en las figuras 4, 5, 6 y 7 que aparecen a continuación de las tablas). Los resultados muestran que

10. Los casos de Córdoba y M álaga se basan, respectivamente, en los capítulo décimo y undé cimos de $\mathrm{N}$ avarro (1999). En su primer capítulo puede encontrarse el diseño de la investigación en su conjunto, donde se incluyen dos casos italianos (V icenza y Bologna). Q uisiera agradecer a estas corporaciones municipales la ayuda y apoyo prestados para realizar este estudio. 
Tabla 1 El sesgo participativo en Córdoba: actores y coaliciones (1979-1995).

\begin{tabular}{|c|c|c|c|c|c|}
\hline & & & & $\begin{array}{l}\text { Commictad } \\
\text { política } \\
\text { participativa }\end{array}$ & $\begin{array}{l}\text { Comunidad } \\
\text { política } \\
\text { indiferenciada }\end{array}$ \\
\hline \multirow[t]{7}{*}{ ACTORES } & \multirow{2}{*}{\multicolumn{3}{|c|}{$\begin{array}{l}\text { CLASE } \\
\text { POLÍTICA }\end{array}$}} & \multirow{2}{*}{\multicolumn{2}{|c|}{ Gobierno municipal (PCE/IU) }} \\
\hline & & & & & \\
\hline & \multirow[t]{5}{*}{ ÉLITES CÍVICAS } & & & AA.VV. & Resto de asociaciones \\
\hline & & \multirow[t]{3}{*}{$\begin{array}{l}\text { Coeficiente } \\
\text { deinfluencia }\end{array}$} & Nive & Alto & $\begin{array}{l}\text { Peñas: alto } \\
\text { APAS: medio } \\
\text { Resto: bajo }\end{array}$ \\
\hline & & & $\mathrm{Pi}$ & 33,06 & $\begin{array}{l}\text { Peñas: } 29,29 \\
\text { APAS: } 17,55 \\
\text { Resto: }[1,22 ; 8,98]\end{array}$ \\
\hline & & & Tpi & 10,50 & $\begin{array}{l}\text { Peñas: } 4,8 \\
\text { APAS: } 21.4 \\
\text { Resto: }[1,7 ; 13,6]\end{array}$ \\
\hline & & \multicolumn{2}{|l|}{$\begin{array}{l}\text { Coeficiente } \\
\text { deconfianza }\end{array}$} & Alto y selectivo & Bajo y difuso \\
\hline \multicolumn{4}{|c|}{ UNIDAD ORGANIZATIVA MUNICIPAL DE REFERENCIA } & $\begin{array}{l}\text { Participación } \\
\text { ciudadana }\end{array}$ & $\begin{array}{l}\text { Depende de la actividad } \\
\text { que desarrolle g grupo }\end{array}$ \\
\hline
\end{tabular}




\begin{tabular}{|c|c|c|c|c|c|}
\hline \multirow[t]{4}{*}{$\begin{array}{l}\text { OPORTUNIDADES } \\
\text { DE } \\
\text { PARTICIPACIÓN }\end{array}$} & \multirow[t]{3}{*}{ FORMA } & \multicolumn{2}{|l|}{ Reglas } & $\begin{array}{l}\text { De carácter formal: } \\
\text { - RPC (Consejos } \\
\text { deDistrito) } \\
\text { - Consejos de Centro }\end{array}$ & $\begin{array}{l}\text { No existen o son de } \\
\text { carácter informal }\end{array}$ \\
\hline & & \multirow[t]{2}{*}{ Procesos } & $\begin{array}{l}\text { Acceso a toma de } \\
\text { decisiones (órganos } \\
\text { de participación) }\end{array}$ & $\begin{array}{l}\text { IRi CD: } 29.33 \\
\text { IRi CC: } 45.23\end{array}$ & $\begin{array}{l}\text { IRi CD: }[-12.70 ; 5.77] \\
\text { IRi CC: [-21.03; 12.93] }\end{array}$ \\
\hline & & & $\begin{array}{l}\text { Acceso a recursos } \\
\text { (subvenciones) }\end{array}$ & IDASi: 16.33 & IDASi: [-10.31; 1.53] \\
\hline & INTENS & do deinst & alización) & Alto & Bajo \\
\hline
\end{tabular}

- Pi: Peso de grupo i sobre el total de grupos existentes en el municipio (en \%).

- Tpi: Tasa de pertenencia del grupo i (porcentaje de población de 18 y más años afiliados al grupo i ).

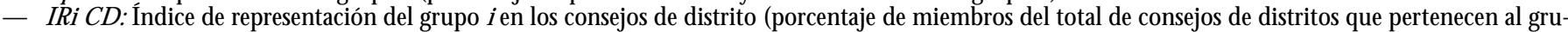
po i menosel peso del grupo i)

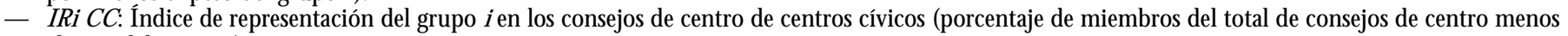
e peso del grupo i ).

El recorrido de estos índices es el intervalo [1,-1]. Cuando el valor es igual a cero significa que el grupo i está representado en los órganos de participa

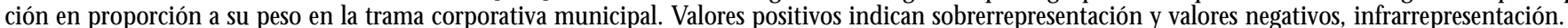

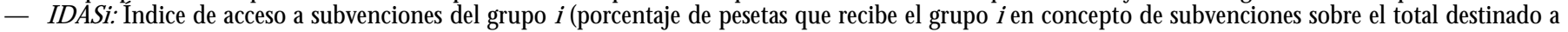
subvenciones menos e porcentaje que representa e grupo i sobre e total de grupos subvencionados).

EI IDAS tiene un recorrido igual al intervalo [100,-100]. Cuando el valor es cero significa que el grupo i recibe una cantidad de dinero que seajusta al

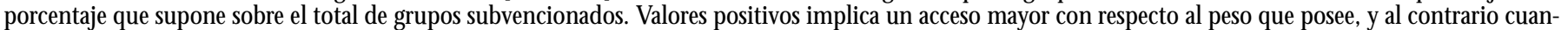
do ed valor es negativo.

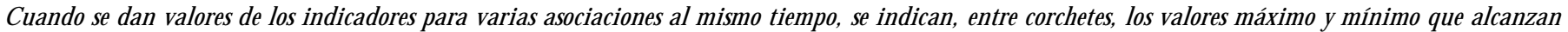
[mín., máx.] 
Tabla 2. El sesgo participativo en Málaga: actores y coaliciones (1979-1995).

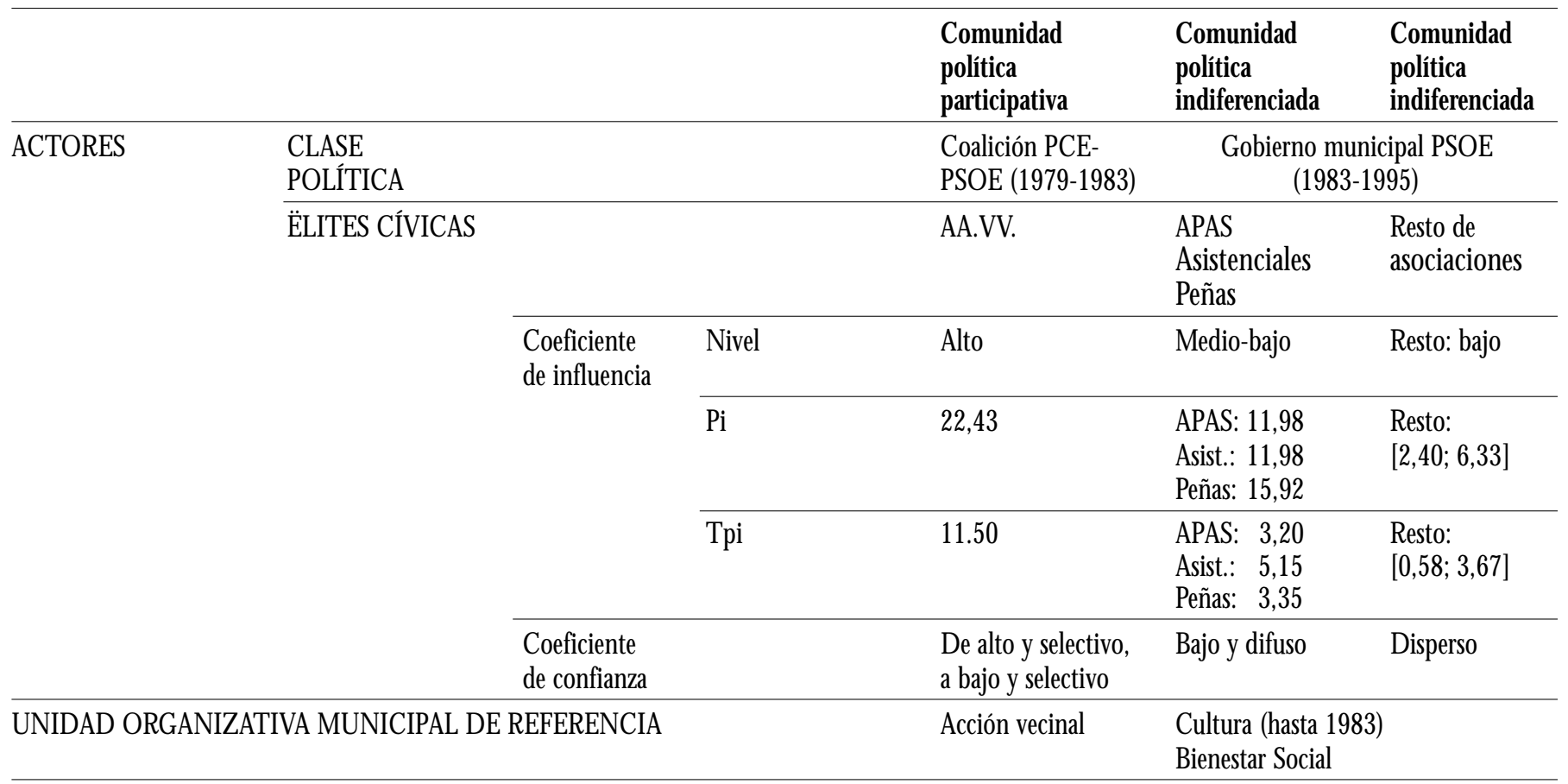




\begin{tabular}{|c|c|c|c|c|c|c|}
\hline \multirow{4}{*}{$\begin{array}{l}\text { OPORTUNIDADES } \\
\text { DE } \\
\text { PARTICIPACIÓN }\end{array}$} & \multirow[t]{3}{*}{ FORMA } & \multicolumn{2}{|l|}{ Reglas } & $\begin{array}{l}\text { Decarácter formal } \\
\text { Plenos de distrito. }\end{array}$ & \multicolumn{2}{|c|}{$\begin{array}{l}\text { Decarácter formal: } \\
\text { Consejos sectoriales }\end{array}$} \\
\hline & & \multirow[t]{2}{*}{ Procesos } & $\begin{array}{l}\text { Acceso a toma de } \\
\text { decisiones (órganos } \\
\text { de participación) }\end{array}$ & IRi PD: 46,32 & $\begin{array}{l}\text { IRi PD: } \\
\text { APAS: 9,38 } \\
\text { Asist: } 6,25 \\
\text { Peñas: }-12,79\end{array}$ & $\begin{array}{l}\text { IRi PD: } \\
\text { Resto: } \\
{[-17,23 ;-7,96]}\end{array}$ \\
\hline & & & $\begin{array}{l}\text { Acceso a recursos } \\
\text { (subvenciones) }\end{array}$ & IDASi: 14,49 & $\begin{array}{l}\text { IDASi: } \\
\text { APAS: }-8,53 \\
\text { Asist.: } 21,96\end{array}$ & $\begin{array}{l}\text { IDASi: } \\
\text { Resto: } \\
{[-6,50 ;-0,90)}\end{array}$ \\
\hline & \multicolumn{3}{|c|}{ INTENSIDAD (grado de institucionalización) } & En descenso & Baja & Ninguna \\
\hline
\end{tabular}

- Pi: Peso de grupo i sobre ed total de grupos existentes en el municipio (en \%).

- Tpi: Tasa de pertenencia del grupo i (porcentaje de población de 18 y más años afiliados al grupo i ).

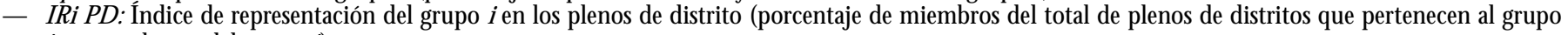
i menose peso de grupo i).

El recorrido de estos índices es el intervalo [1,-1]. Cuando el valor es igual a cero significa que el grupo i está representado en los órganos de participa

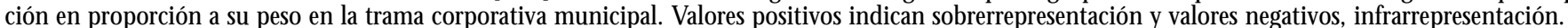

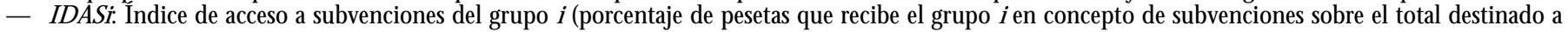
subvenciones menos e porcentaje que representa e grupo i sobre $\mathrm{d}$ total de grupos subvencionados).

EI IDAS tiene un recorrido igual al intervalo [100,-100]. Cuando el valor es cero significa que el grupo i recibe una cantidad de dinero que seajusta al

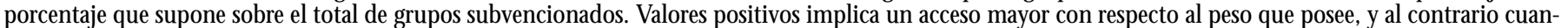
do ed valor es negativo.

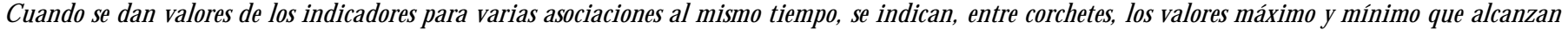
[mín., máx.] 


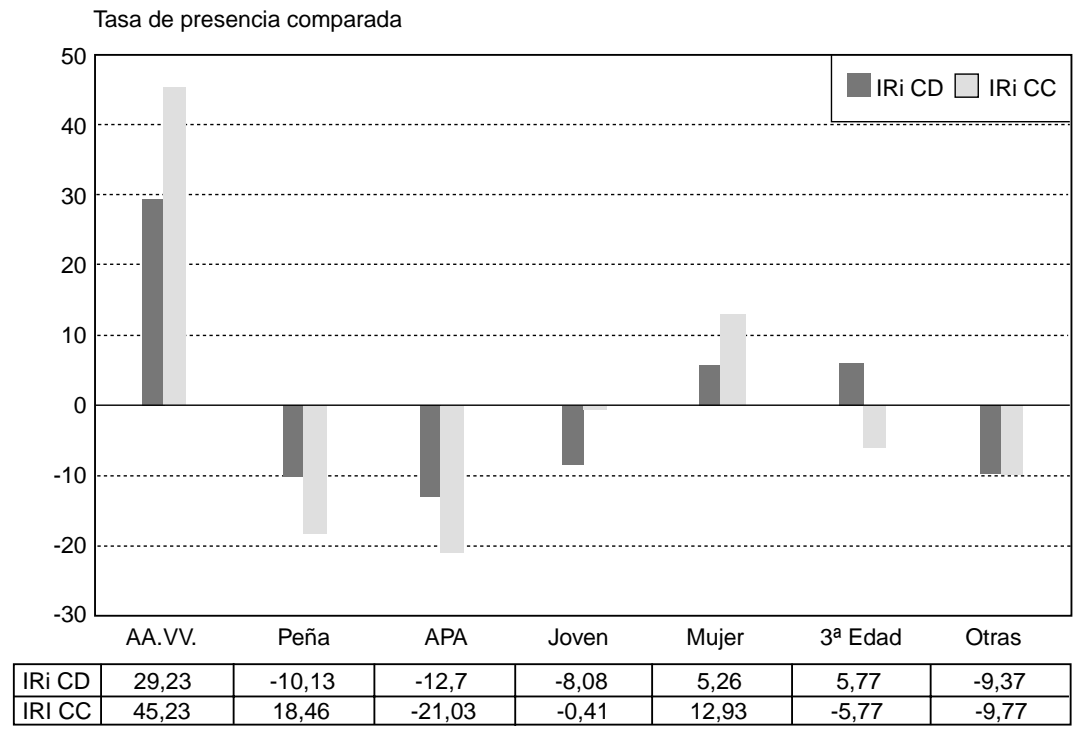

Figura 4. Índices de representación en consejos de distrito y consejos de centro en el municipio de Córdoba (1995).

Fuente: $N$ avarro (1999: 225 y 236).

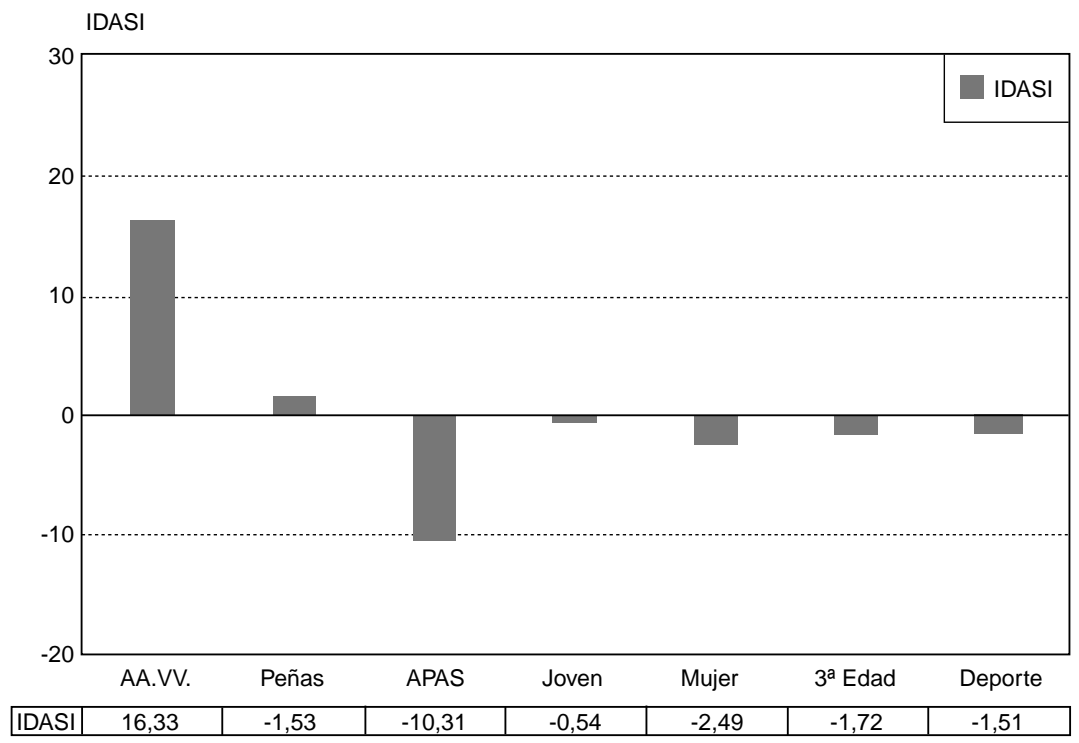

Tipos de colectivos

Figura 5. Índice de acceso a subvenciones de centros cívicos por tipo de asociaciones en Córdoba (1991-1993).

Fuente: $\mathrm{N}$ avarro (1999: 237). 


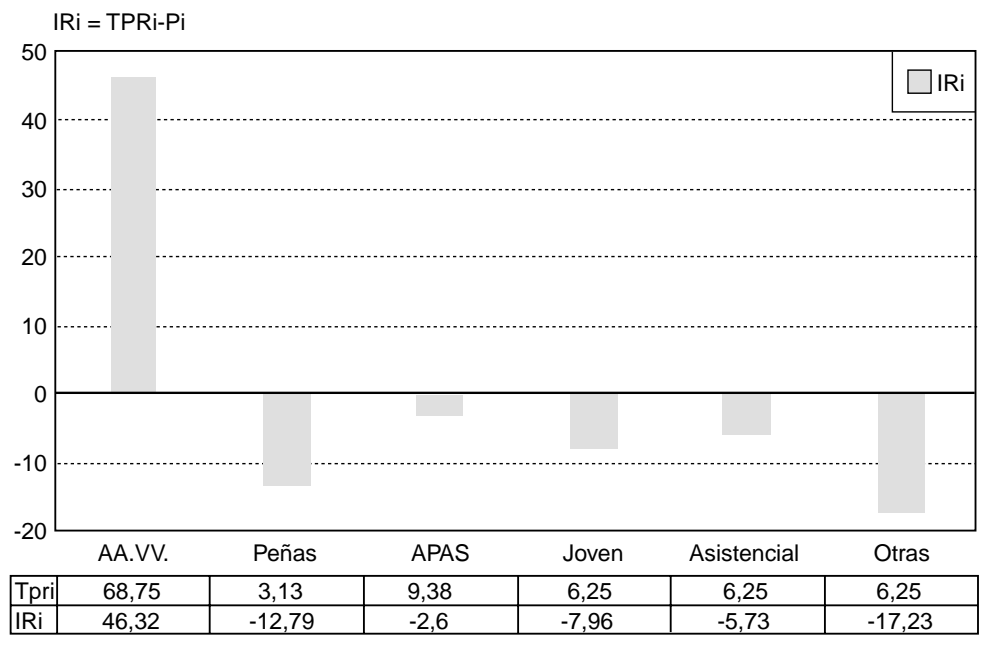

Tipos de colectivos

IRi: índice de representación del colectivo I en pleno de distrito. TPRi: tasa de presencia del colectivo I en pleno de distrito.

Figura 6. Índice de representación en los plenos de distrito de M álaga (1996).

Fuente: $N$ avarro (1999: 266).

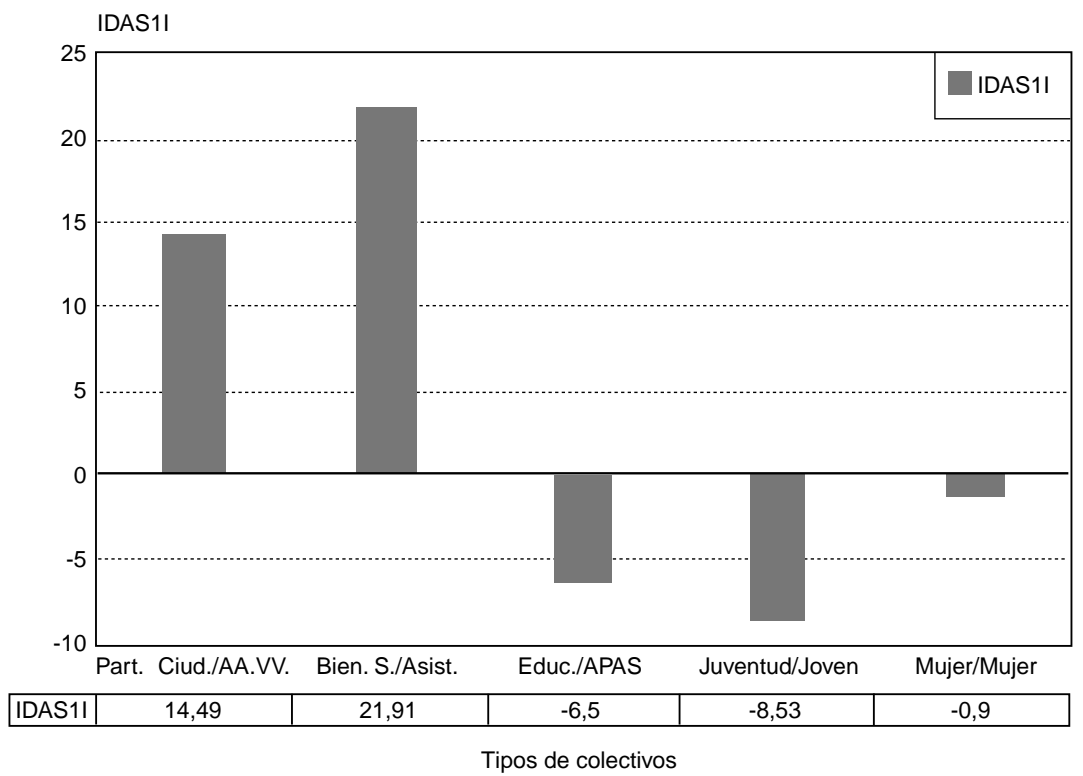

Figura 7. Índice de acceso a subvenciones municipales en M álaga (1993-1995).

Fuente: $N$ avarro (1999: 267). 
cuanto mayores son las primeras, también lo son las segundas, confirmando así nuestra hipótesis del sesgo participativo. Ahora bien, ¿cómo se genera en cada municipio la coalición que da lugar a este sesgo?

En el caso de Córdoba, puede explicarse porque la corporación municipal tenía información acerca de la afinidad de las asociaciones de vecinos, basada en una amplia superposición de sus miembros con el PCE. Aún manteniendo su independencia de criterio, las AA.VV estuvieron ligadas desde su origen a la órbita del partido comunista y de otros partidos de izquierda. Sin embargo, esta interrelación fue diluyéndose a medida que se afianzaba la democracia en España: muchos de los partidos de izquierda más activos desaparecieron, el PCE perdió en las urnas buena parte de su fuerza e influencia y el movimiento vecinal se fue despolitizando gradualmente (C astell, 1986: 318-319; Gunther y otros, 1986: 176).

Ahora bien, la permanencia del PCE y posteriormente I zquierda Unida en la al caldía de Córdoba hasta las elecciones de 1995, no sólo permitió que aquella relación privilegiada (aunque independiente) entre el PCE y el movimiento vecinal no desapareciera, sino que las AA.VV. encontraron en el poder municipal mayor fomento que otras asociaciones locales. Tal y como apunta el antiguo secretario de la Federación Cordobesa de Asociaciones de Vecinos «la mayoría de las AA.VV. están nutridas por gente de IU y por cristianos progresistas». Aunque el gobierno municipal de Córdoba no tuviera información completa sobre toda la trama asociativa de la ciudad, sí la tenía sobre las AA.VV. Sabe que aproximadamente un cuarto del total de asociaciones de la ciudad son de vecinos - coeficiente de influencia - y tiene la seguridad de que apoyarán su política si las fomenta - tiene la seguridad de que son afines, coeficiente de confianza - y en ellas sustenta, como queda reflejado en la tabla 1, el desarrollo de instituciones de participación ciudadana.

Este sesgo en la oferta de oportunidades de participación dio lugar a la creación de una comunidad política participativa integrada por la coalición vecinal y comunista, que impulsa, desarrolla y casi monopoliza la oferta institucional de oportunidades de participación. El resto de asociaciones, con bajos coeficientes de confianza e influencia (a excepción de las peñas), se integran en una comunidad política indiferenciada. Sus actores corporativos poseen menor acceso a las oportunidades de participación e interactúan con el gobierno municipal mediante mecanismos y acuerdos no regulados institucionalmente, y en gran medida, fuera del departamento de participación ciudadana, desde el que se desarrolla la política pública de participación.

Lo expuesto muestra que antes de decidir si fomentará o no la participación, o si privilegiará en mayor medida a unas asociaciones que a otras, el partido o coalición en el gobierno municipal tratará de conocer los coeficientes de confianza e influencia de las asociaciones locales. En este sentido resultan muy aclaradoras las declaraciones de un concejal del PSO E responsable del área de participación del Ayuntamiento de M álaga desde los años ochenta: 
El colectivo de jubilados [... ] depende de quien le dé. Fundamentalmente en las clases más modestas derivan todos hacia el PSOE. El colectivo de jóvenes [... ] ¡D ios supiera, D ios supiera! Las culturales [... ] depende. Las muje res [... ] son progresistas. Pero normalmente el movimiento es mucho más radicalizado».

Es precisamente a partir de este conocimiento que el gobierno municipal decidirá que sentido adopta el sesgo participativo. Precisamente el caso de M álaga permite ilustrar la estrategia de un gobierno municipal que cree que las asociaciones más numerosas de la ciudad (un alto coeficiente de influencia) y que cuentan con un mayor grado de representación en los órganos de representación, las de vecinos, le son adversas (un bajo coeficiente de confianza).

Entre 1979 y 1995 el gobierno municipal malagueño pasa por dos etapas. H asta 1983 PCE y PSO E forman una coalición de gobierno, que se quie bra cuando el segundo logra gobernar en solitario desde esa fecha, y hasta 1995. D urante la primera etapa el ejecutivo y las asociaciones de vecinos forman una coalición cohesionada para aprobar y poner en marcha el RPC. M ás concretamente, la afinidad existente entre estas asociaciones y uno de los miembros de la coalición, el PCE, permite - como en el caso de Córdobaque la oferta de oportunidades de participación favorezca a estas asociaciones frente a otras, como puede apreciarse en el número de representantes que unas y otras poseen en los plenos de distrito (tabla 3$)^{11}$.

Sin embargo, el triunfo electoral del PSO E en 1983 por mayoría absoluta obliga a este partido a plantearse una estrategia diferente: 0 bien deja de ofrecer oportunidades de participación, cuestión descartada bien pronto, 0 bien debe buscarse nuevos aliados para formar una coalición frente a las $A A . V V{ }^{12}$. Y ello porque se tiene la convicción de que este actor corporativo no es afín a la nueva mayoría y puede socavar el consenso electoral recientemente obtenido:

11. En el momento en que se redacta y se aprueba el primer RPC el concejal responsable de participación - Acción Vecinal- es del PCE, y los miembros de la Federación de la AA.V V. son cercanos a ese partido. Este concejal señala en una de las entrevistas realizadas: «Entonces se elaboraron los primeros documentos de participación. Q ue me encargo yo de elaborar junto con la Federación de AA.VV., que también lógicamente al frente de la federación había otro del Partido Comunista, que... que esto era así entonces».

12. Frente a miembros del PSOE que siguen apostando por la participación, otros creen que las elecciones los legitiman para gobernar la ciudad sin contar con la participación de las asociaciones locales. Un concejal del PSO E responsable del Área de Participación señalaba en una entrevista: «Pero bueno, vuelvo a decir que tengo compañeros que, con todo el respeto que se merecen, que decían: "H emos ganado las elecciones" [... ] Aquí ha habido compañeros que [... ] unas elecciones, y se ríen de ti [por fomentar la participación]. " ¿Y qué hacen estos tíos [representantes de asociaciones locales] opinando de [las decisiones políticas]?"». 
El movimiento asociativo de vecinos, su creación no es del PCE, pero el PCE lo convierte en arma suya. Cuando comienzan las primeras el ecciones, fue su caballo de batalla [... ] y por eso, pues pretenden manipular todo lo que sea colectivos asociativos, fundamentalmente centrándose en las AA.VV.» (Concejal del PSOE responsable del Área de Participación).

Con independencia de que ello sea cierto o no, el caso es que el partido en el gobierno municipal lo cree aś, y por ello intenta contrarrestar la capacidad de influencia del movimiento vecinal mediante una reforma del Reglamento de Participación que dé cabida a nuevos grupos ${ }^{13}$. En concreto, el PSO E trata de dar mayor representatividad en los plenos de distrito a las asociaciones de padres de alumnos (APAS), por considerarlas más afines:

Las APAS tenían una federación muy del PSOE [... ] Cuando empecé a movilizar a los movimientos sectoriales fui colegio por colegio fomentando la existencia de APAS, como yo decía, creando al enemigo» (concejal del PSOE responsable de Participación Ciudadana. Cursiva nuestra).

Esta estrategia también trata de ponerse en marcha posteriormente con respecto a las asociaciones de carácter asistencial. Para ello, además, se intentan potenciar consejos sectoriales en relación con diversas áreas municipales (Educación y Servicios Sociales), para crear así un ámbito institucional adecuado y autónomo para este tipo de asociaciones.

La oposición de las AA.VV. a la reforma del Reglamento ${ }^{14}$ y la debilidad de las APAS y asociaciones asistenciales como aliado (en la medida en que presentan menores coeficientes de influencia y las políticas de servicios sociales y de educación no son competencia exclusiva municipal), hace que la estrategia del PSOE no tenga pleno éxito. Como se ve en la tabla 3, aunque las sucesivas reformas del RPC no merman la representatividad de las AA.VV.

13. Sobre la conveniencia o no de fomentar a partir de 1983 la participación ciudadana, un responsable del PSOE nos dice: «Yo recuerdo que aquí quisimos mover el tema de las asociaciones y de las subvenciones, pero hace ya años. " $Q$ ué queréis, poner un sueldo a los del PCE?". Esa fue la contestación oficial del PSOE, te estoy hablando del PSOE [... ] "Entonces ¿[es] que le queréis poner un sueldo a los liberados?, ¿queréis liberar a la gente del PCE ?". Era una actitud muy razonable porque era verdad».

14. «Al principio la primera batalla que se libró fue que la Federación de Vecinos quería más o menos la exclusiva» (concejal del PSOE del Área de Participación Ciudadana). En opinión de las AA.VV., el PSO E trata de limitar su papel mediante la reforma del R PC, a lo cual se oponen: «[... ] revisando el documento [el nuevo RPC] pues nos tiramos un año, donde veíamos cómo todo aquel espíritu del primer documento que había nacido propiciado por el movimiento vecinal de M álaga, pues se nos va cortando. El documento que se aprobó no era el documento que queríamos el movimiento vecinal en M álaga» (ex-concejal de IU y miembro de la Federación de AA.VV.) «Es importante que estén [otras asociaciones], pero que aquí si alguien había luchado por la participación eran las AA.VV., y por lo tanto entendíamos que eran las que tenían, un poco, que dirigir el proceso» (miembro de la Federación de AA.VV.). 
Tabla 3. Composición de los plenos de distrito en el municipio de M álaga entre 1979 y 1995.

\section{Reglamento}

1981

1983

\section{Composición de plenos de distrito}

Presidente: concejal nombrado por el alcalde.

Vocales: cada partido en proporción al Pleno Municipal.

1 miembro por cada AA.VV.

1 miembro de la Federación de AA.VV.

1 miembro por todas las APAS.

3 miembros de entre el resto de asociaciones.
1984

1988
Presidente: concejal nombrado por el alcalde.

Vocales: cada partido en proporción al Pleno Municipal.

1 miembro por cada AA.VV.

1 miembro de la Federación de AA.VV.

2 miembros de las APAS.

1 miembro de la Federación de APAS.

1 miembro por cada uno de los otros tipos de asociaciones.

1995
Presidente: concejal nombrado por el alcalde.

Vocales: cada partido en proporción al Pleno Municipal.

1 miembro por cada AA.VV.

1 miembro de la Federación de AA.VV.

2 miembros de las APAS.

1 miembro de la Federación de APAS.

1 miembro de la Federación de Peñas.

2 miembros por cada uno de los otros tipos de asociaciones.

en términos absolutos, la diluyen incrementando la presencia de representantes de otras asociaciones. Aún así, en la tabla 2 y la figura 6 se aprecia, mediante el índice de representación ( $\left(R_{\mathrm{i}}\right)$, que a mediados de los noventa las AA.VV. siguen estando sobrerrepresentadas en relación con las demás asociaciones locales.

El mismo fenómeno parece producirse con respecto al acceso a subvenciones (figura 7). Aunque en términos absolutos el gobierno municipal de Málaga no reduce la cantidad de recursos económicos que concede a las AA.VV. a través de subvenciones, lo hace en términos relativos. Así, estas asociaciones pasan de recibir el 34\% del total de las subvenciones en 1993, a recibir el $20,5 \%$ en 1995 . En cambio, para el resto se producen progresivamente ciertos incrementos ( $N$ avarro, 1999: 268).

El resultado de estas estrategias, que implican el esfuerzo por cambiar a los integrantes de la coalición y, por tanto, el sentido del sesgo participativo existente en el origen, produce la formación de al menos tres comunidades políticas (tabla 2). La primera, formada por la coalición originaria - coalición 
PCE-PSO E y AA.VV.- , donde actores corporativos, con un alto coeficiente de influencia, y clase política mantienen un alto grado de superposición. Sus relaciones se establecen mediante pautas estables y a través de los plenos de distrito y el $D$ epartamento de Acción Vecinal. Esta comunidad política pre senta cierto proceso de desinstitucionalización a partir del cambio electoral de 1983, cuando merma el coeficiente de confianza de las AA.VV.

En segundo lugar, diversas coaliciones sectoriales minoritarias - PSO E y diversas asociaciones de carácter sectorial- caracterizadas por el bajo coeficiente de influencia de los actores corporativos, pero un al to coeficiente de confianza. M antienen relaciones estables a través de consejos sectoriales y el D epartamento de Cultura y Participación Ciudadana (posteriormente Bienestar Social y Participación Ciudadana). Esta comunidad política presenta un bajo nivel de institucionalización a causa de la debilidad de los aliados corporativos y la oposición de las AA.VV.

Por último una comunidad política indiferenciada, en donde gobierno municipal y actores corporativos (minoritarios en su influencia y en su confianza), mantienen relaciones ad hoc, ni estables ni formalizadas, en función de cuestiones concretas, sin que hayan alcanzado, pues, ningún grado de institucionalización.

\section{El sesgo participativo: límites estructurales a la democracia participativa}

C omo se ha visto, las experiencias de democracia participativa en municipios españoles pueden tomarse como una aplicación aproximada de las propuestas normativas de democracia asociativa. Se trata de reformas institucionales que suponen la complementación de la poliarquia electoral con ciertas oferta de oportunidades de participación a grupos y asociaciones locales, sin que esto suponga poner en cuestión que el ejercicio del poder político se legitime por los procesos y mecanismos institucionales que configuran el modelo que se pretende complementar, ya que existe consenso acerca de que éste, aunque con limitaciones, garantiza los postulados normativos democráticos.

Ahora bien, se ha comprobado la aparición de cierto sesgo participativo en todos los municipios analizados, por el que parte de la ciudadanía, parte de los grupos que pretenden hacer valer sus intereses, quedan excluidos o se benefician en menor medida que otros del acceso al gobierno municipal, Io que supone la limitación del proceso democratizador que éste pretende desarrollar.

Tal y como postulábamos, el sesgo es resultado de la oportuna, y por tanto contingente, agregación de los recursos de actores electorales y corporativos poderosos para configurar una coalición que garantice una solución favorable al dilema que plantea para el gobierno municipal la provisión del bien «oportunidades de participación política». Puede argumentarse, pues, que el sesgo participativo es el resultado de la aplicación de estrategias de oportunismo político a la resolución del dilema que representa para el gobierno local ofrecer 
oportunidades de participación al mismo tiempo que pretende ganar las elecciones. Aún más, el sesgo participativo es un resultado institucionalmente inducido por el propio marco institucional que se pretende modificar, la poliarquía el ectoral. Con cierta independencia de los intereses originarios de los actores, el requerimiento institucional de ésta - victoria electoral - a sus actores centrales, los partidos, genera una estrategia adaptativa - el sesgo participativo- por la que se limita el alcance de la iniciativa democratizadora.

Así pues, el desarrollo de la democracia asociativa, la complementación de la poliarquía electoral mediante la participación activa de grupos de interés, parece encontrar límites estructurales derivados, ya no sólo del tamaño de la comunidad política, sino sobre todo de la estructura institucional que pretende transformar. Ésta última condiciona, o al menos induce, los resultados de procesos de democratización. Los gobiernos municipales tienden a ofrecer oportunidades de participación siempre y cuando esto no afecte negativamente a su legitimidad el ectoral. Aunque sea porque, al límite, para ofrecerlas necesitan estar en posición de hacerlo.

Esta limitación a los procesos de democratización municipal permite concluir que a la conocida paradoja democrática de la participación, se puede añadir la que podríamos denominar paradoja de la democratización. Los ciudadanos, aparte de votar, por lo común, no participan políticamente, aunque normativamente esto sea una exigencia del gobierno democrático (primera paradoja); pero además, cuando lo hacen, se ven limitados, al igual que los propios partidos, la clase política, por los criterios que impone la lucha y la victoria electorales. Su participación y acceso a los procesos de toma de decisiones están condicionados por ello (segunda paradoja).

\section{Bibliografía}

BALME, R. (1989). «Councillors, issue agendas and political action in tow French towns». En M ABILEAU y otros (ed.). Local Politics and Participation in Britain and

France. Cambridge: Cambridge University Press.

BARBER, J. (1986). Strong D emocracy. Berkeley: Berkeley University Press.

BetTIN, G . (1993). Classe politica e città. M ódena: CED AM.

BOLDUC, V. (1980). «Representation and legitimacy in neighborhood organizations:

a case study». Journal of Voluntary Action Research, núm. 9, p. 165-178.

CAPó y otros (1988). «La formación de una élite política local». Revista de Estudios

Políticos, núm. 59, p. 199-222.

CASTELLS, M . (1986). La ciudad y las masas. M adrid: Alianza Editorial.

COHEN, J.; Rogers, J. (1995). «Secondary Associations and D emocratic Governance». En W RIGTH, E.O. (ed.). Associations and Democracy. Londres: Verso, p. 7-100.

D AHL, R. (1982). Dilemmas of Pluralist D emocracy, N ew H aven, Yale University Press.

Dahl, R.; Tufte, R. (1973). Size and Democracy. Stanford: Stanford University Press. 
DIAM OND, L. (1994). «ntroduction: Political Culture and Democracy». En DIAMOND, L. (ed.). Political Culture and D emocracy in D eveloping Countries. Boulner-London: Lynne Rienner Publishers.

DowDIng, K. (1991). Rational Choice and Political Power. Aldershot: Edward Elgar.

D ow N S, A. (1973). Teoría económica de la democracia. M adrid: Aguilar.

- (1991). «Una teoría económica de la acción política en una democracia». En Colomer, J. (comp.). Lecturas de teoría política positiva. Madrid: Instituto de Estudios Fiscales, p. 263-298.

Elster, J. (1989). Nuts and Bolts for the Social Sceience. Cambridge: Cambridge University Press.

Fundación En CUENTRo (1994). España 1994. M adrid: Fundación Encuentro.

- (1995). España 1995. M adrid: Fundación Encuentro.

Gunther, R.; SAN I, G. y SABAH, G . (1986). El sistema de partidos políticos en España: génesis y evolución. M adrid: CIS.

H ARDIN, R. (1982). Collective Action. Londres: The Johns H opkins U niversity Press. H ELD, D. (1986). «ntroduction». En HeLD, D .; Pollit, C. (ed.). N ew Forms of D emocracy. Londres: Sage.

H IRST, P. (1994). Associative D emocracy. Londres: Polity Press.

- (1995). «C an Secondary Associations Enhace D emocratic Governance? En CoH EN, J.; Rogers, J. (ed.). Associations and D emocracy. Londres, Verso, p. 101-113.

Kelso, W.A. (1978). American D emocratic Theory. Londres: Greenwood Press.

KLANDERmans, B.; ONEAGA, D. (1987). «Potentials, networks, motivations, and barriers, steps towards participation in social movements», American Sociological Review, núm. 52, p. 519-531.

K N OKE, D. (1990). Political N etworks. The Structural Perspective. Cambridge: Cambridge U niversity Press.

K N OKE, D .; KUKLIN SKI, J. (1982). N etwork Analysis. Londres: Sage.

LANZALACO, L. (1995). Istituzioni, O rganizzazione, Potere. Roma: La N uova Italia Scientifica.

M AN SBRID GE, J. (1995). «A D eliberative Perspective on N eocorporatism». En C O HEN , J.; Rogers, J. (ed.). Associations and Democracy. Londres, Verso, p. 133-147.

M ARTIN , M .; FRAN CESCUTI, P. (1993). «Asociacionismo en el municipio de M adrid». Alfoz: núm. 104-105, p. 97-102.

M ARWelL, G.; O Liver, P. (1993). The Critical M ass in Collective Action. C ambridge: C ambridge University Press.

M OYSER, G.; PARRY, G. (1989). «C ouncillors, citizens and agendas: aspects of local decision-making in Britain». En M ABILEAU, A. y otros (ed.). Local Politics and Participation in Britain and France. Cambridge: Cambridge University Press.

N avarro, C.J. (1994). Encuesta de la FEM P sobre Participación Ciudadana a los municipios españoles. Córdoba: Documento de Trabajo del IESA de Andalucía/C SIC.

- (1997a). «O portunidades para la democratización en los municipios españoles». Revista Internacional de Sociología, núm. 17, p. 65-81.

- (1998). El nuevo localismo. D emocracia y municipio en la sociedad global. Córdoba: Diputación de Córdoba. 
- (1998a). «Límites al nuevo localismo: gobierno municipal de las democracias occidetales en perspectiva comparada». Revista de Estudios Políticos, núm. 100, p. 272-290.

- (1999). El sesgo participativo. M adrid: CSIC.

O LIVER, P. (1984). «"If you don't do it nobody else will": active and token contributors to local collective action». American Sociological Review, núm. 49, p. 601-610. O RDESH O OK, P. (1992). A Political Theory Premier. Nueva York: Routledge.

O WEN S, J.E. (1988). «Te Importance of C andidate C haracteristics and Local Political Conditions in the 1994 U S M id-Term Elections». Political Studies, XLVI, p. 766-776.

PARRY, G .; M OYSER, G .; D AY, N . (1992). Political Participacion and D emocracy in Britain. C ambridge: Cambridge University Press.

Pietro-LACACI, R. (1994). «Asociaciones Voluntarias». En CAM Po, S. Del (ed.).

Tendencias Sociales en España (1960-1990). M adrid: Fundación BBV, p. 197-218. RAO, N. (1998). «Representation in Local Politics: a Reconsideration and some N ew Evidence». Political Studies, XLVI, p. 19-35.

SARTORI, G. (1987). Elementi di teoria politica. Bolonia: II M ulino.

- (1988). Teoría de la democracia. M adrid: Alianza.

SAST RE, C.: «La transición política en España: una sociedad desmovilizada». Revista

Española de Investigaciones Sociológicas, núm. 86, p. 3-68.

SCH M ITTER, PH.C. (1992). «nterest System and the Consolidation of D emocracies».

En M ARKS, G.; D IAM OND, L. (ed.). Reexamining D emocracy. Londres: Sage.

- (1988). «C orporative D emocracy: O xymoronic? Just Plain M oronic? O r A Promosing Way O ut of the Present Impasse?». Woking Paper, Stanford University.

- (1995). «T he I rony of M odern D emocracy and the Viability of Efforts to Reform its Practice». En COHEN, J.; Rogers, J. (ed.). Associations and D emocracy. Londres: Verso, p. 167-183.

TILlY, Ch. (1978). From M obilization to Revolution. Londres: Addison-Wesley. U RRUTIA, V. (1992). «Transformaciones y persistencias de los movimientos sociales urbanos». Política y Sociedad, núm. 10, p. 49-56.

VILLASANTE, T. (1984). Comunidades Locales. M adrid: IN AP. 